\title{
Metacognitive Strategy Preference in Vocabulary Learning among Iranian EFL Learners
}

\author{
Elham Entesari \\ Aras International Campus \\ University of Tabriz, Tabriz, Iran \\ Mohammad Zohrabi \\ English Department, \\ Faculty of Persian Literature and Foreign Languages \\ University of Tabriz, Tabriz, Iran
}

\begin{abstract}
This study aimed to investigate the use of metacognitive strategies in vocabulary learning by Iranian EFL learners. Precisely, it tried to examine intermediate and advanced learners' use of metacognitive and cognitive strategies in vocabulary learning. To achieve this aim 120 (i.e. 60 intermediate and 60 advanced) Iranian EFL learners were randomly selected after administering the Nelson English Language Test. Then, Schmitt's Vocabulary Learning Strategies (VLS) test was administered to the students. The findings showed that cognitive strategies were preferred by intermediate learners and metacognitive strategies were favored by advanced learners.
\end{abstract}

Keywords: vocabulary learning strategies, metacognitive strategies, cognitive strategies

\section{INTRODUCTION}

Vocabulary is an essential part of communication without which people cannot convey their messages. In written text, in face to face communication, in class activities and in real life, learners often encounter unfamiliar words and phrases that hinder their language comprehension. Learners experience situations where limitations in their language competence prevent them from expressing themselves effectively (William, 2006).

\section{REVIEW OF THE RELATED LITERATURE}

Vocabulary and language have a reciprocal impact on each other. Vocabulary knowledge helps language use and language use helps the increase of vocabulary knowledge (Nation, 2001). According to Nation (2001), vocabulary learning strategies are one of the most important parts of language learning strategies which in turn are parts of general learning strategies. Research has demonstrated that many students use a wide variety of strategies when learning vocabulary especially in tasks such as listening and speaking. But learners mostly use basic vocabulary learning strategies (Schmitt, 1997).

Cognitive strategies are mechanical aspects of learning vocabulary such as taking notes and highlighting new words, making lists of new words, using flashcards to record new words, putting English labels on physical objects, keeping vocabulary notebooks, and writing the words many times. Metacognitive strategies, on the other, involve monitoring, decision- making and assessing one's progress. They help learners to specify suitable vocabulary learning strategies for learning new words (Schmitt, Vocabulary in language teaching, 2000). 
In the present study, the researcher aimed to consider the application of these strategies in learning vocabulary and wishes to specify the use of metacognitive and cognitive strategies across intermediate and advanced levels proficiency. Vocabulary learning seems to be a neglected area in literature and there is a need for more research in this field (Xhaferi \& Xhaferi, 2008).

Richards and Renandaya (2002) noticed the fact that vocabulary education was given little priority in second language programs and vocabulary acquisition was put aside and received no attention in many textbooks and language programs. Hedge (2001, p. 110) complained about neglecting vocabulary saying that "in the literature of language teaching and learning, a recurring theme has been the neglected of vocabulary". He also states that this neglect is quite surprising for a couple of reasons. The first reason is that students themselves put noticeable significance on vocabulary. The neglect of vocabulary is also surprising due to the fact that vocabulary errors are more confusing than grammatical ones. It is also obvious that vocabulary learning is an important task for EFL learners Nation (2001, p. 217) defined vocabulary learning strategies as strategies which need to a) involve choice, that is, there are several strategies to choose from, b) be complex, that is, there are several steps in learning, c) result in knowledge and benefit from training, and d) increase the efficiency of vocabulary learning and vocabulary use.

GU, and Johnson (1996) divided vocabulary learning strategies into metacognitive, cognitive, memory encoding and activation strategies. Metacognitive strategies include selective attention and self-initiation strategies. They believe that foreign and second language learners employ selective attention strategies in order to know which words are crucial for them to learn and are important for adequate comprehension of a passage. In order to make the meaning of vocabulary items clear, learners who employ self-direction strategies use a variety of techniques. Cognitive strategies in $\mathrm{Gu}$ and Johnson's taxonomy involve guessing strategies, skillful use of dictionaries and note-taking strategies. Learners who utilize guessing strategies draw upon their background knowledge and also utilize linguistic clues such as grammatical structures of a sentence to guess the meaning of a word. Memory strategies are classified into rehearsal and encoding categories. Word lists and repetition are examples of rehearsal strategies. Encoding strategies are association, imagery, visual, auditory, semantic, and contextual encoding as well as word structure (i.e., analyzing a word in terms of prefixes, stems, and suffixes). Activation strategies involve those strategies through which the students actually use new words in various contexts. A comprehensive inventory of vocabulary learning strategies has been compiled by Schmitt (1997). He classified the strategies into two groups: the ones which identify the meaning of new words when encountered for the first time, and those which consolidate meaning when encountered again. The former involves determination and social strategies and the latter involves cognitive, metacognitive, memory and social strategies. According to Schmitt (1997), determination strategies are utilized when "learners are faced with discovering a new word's meaning without recourse to another person's experience" (p. 205).

Learners try to find the meaning of a word by guessing it with the help of the context, structural knowledge of the language, and reference materials. For Schmitt (1997) the second way to find the new meaning of a word is through using social strategies by asking someone for help with unknown words. Besides the initial discovery of meaning of a word, learners need to use a variety of strategies to practice and retain vocabulary. In this taxonomy, cognitive strategies are similar to memory strategies but do not focus on manipulative mental processing. They involve repetition and use of mechanical means such as word lists, flash cards, and vocabulary notebooks to learn words. Finally, metacognitive strategies in Schmitt's (1997) taxonomy are demonstrated as strategies utilized by students who control and evaluate their own learning such as testing oneself. 
Vocabulary learning is considered as an integral and important area of language teaching as "words are the basic building blocks of language, the units of meaning from which larger structures such as sentences, paragraphs and whole texts are formed" (Read, 2000).

According to Ruutmets (2005), vocabulary learning strategies are a subcategory of learning strategies and create knowledge about what learners do to identify the meaning of new words, retain them in long-term memory, recall them when needed in comprehension, and utilize them in language production.

They are categorized into a) strategies for understanding the words meaning, such as making deductions from the word-form, linking to cognates, guessing from the context and using dictionary, and b) strategies for learning words, such as repeating the word over and over again, organizing words in the mind and linking to background knowledge.

Takac (2008, p. 52) believes that vocabulary learning strategies are "specific strategies utilized in the isolated task of learning vocabulary in the target language" and adds that students can use them in any language learning situation. He also mentioned four characteristics of vocabulary learning strategies as 1) require selection on students' part, 2) exhibit complexity and necessitate certain process, 3) depend upon students' understanding and can further improve through instruction, and 4) make learning and using vocabulary in L2 more efficient.

Schmitt (1997) developed Oxford's (1990) taxonomy for vocabulary learning strategies, and divided vocabulary learning into two main phases: discovering the new meaning of words and consolidating the new word's forms and meanings. During these phases, students utilize different strategies, i,e, cognitive strategies which are accomplished through the process of using or converting the language material, social strategies which are developed through interaction either among students or between teacher and students, and finally, memory strategies which are recalling the meaning of a word based on its decoding and connection with the student's background knowledge. They can be enriched by the students themselves, depending on their individual preferences and learning styles. Metacognitive strategies help students monitor and evaluate their process of learning and use certain techniques consciously which improve performance in the target language. Metacognitive and cognitive strategies are used as a crucial 'key' for students to become more independent and responsible for their own learning, so, students should be encouraged in order to individualize their strategy use, which may vary based on educational, linguistic or cultural background and learning style (Yamato, 2000).

In the current study, which is a mixed methods design, a proficiency test and one questionnaire were used to collect data. The questionnaire which was used in this study is parts of Schmitt's vocabulary learning strategies questionnaire (VLSQ) adopted from Bennett (2006) with a reliability coefficient of 0.72 which was related to metacognitive and cognitive vocabulary learning strategies. So, we gave the participants a questionnaire on the use of metacognitive and cognitive, based on the Schmitt's vocabulary learning strategies.

The participants of the study were 120 Iranian EFL learners within the age range of 19-25. They were 60 intermediate and 60 advanced levels who were selected randomly. A Nelson English Language Test consisting of 50 questions was given to 150 EFL learners attending undergraduate classes at the university to determine their general English language proficiencies. This test was used to enable the researcher to select a homogeneous group. The students who answered 30\% of the questions were considered as intermediate learners and the students who answered $30 \%$ of the questions were 
considered as advanced learners. The students were both female and male, majoring in different fields like English Translation, English Literature, and English Language Teaching.

The second test used in the study was Schmitt's vocabulary learning strategies questionnaire (VLSQ) which is related to metacognitive and cognitive vocabulary learning strategies. Twelve (out of 55) strategies were selected which contained 7 strategies related to cognitive strategies and 5 strategies related to metacognitive strategies. A Likert scale was used to collect the responses. Data were analyzed using the Statistical Package for Social Science (SPSS) version 20. Descriptive statistics and inferential statistics and paired sample t-Test were used to compare and contrast intermediate and advanced learners in terms of use of cognitive and metacognitive strategies. At the end of the study, a chi-square test was used to find out the similarities and differences in terms of use of these strategies for learning vocabulary.

\section{METHODS}

In the current study, which is a mixed methods design, a proficiency test and one questionnaire were used to collect data. The questionnaire which was used in this study is part of Schmitt's vocabulary learning strategies questionnaire (VLSQ) adopted from Bennett (2006) with a reliability coefficient of 0.72 which was related to metacognitive and cognitive vocabulary learning strategies. In this study, only 12 strategies out of 55 strategies were selected which contained seven strategies related to cognitive strategies and five strategies related to metacognitive strategies. There were five alternatives to choose from, i.e., consist of never, seldom, sometimes, often, always. The second instrument which consists of 50 questions used in this study was a Nelson English Language Test for testing learners' proficiency levels.

\section{Results}

\subsection{Metacognitive and Cognitive Strategies in Intermediate Level}

Table 1 shows the means of use of metacognition and cognition strategies by intermediate learners.

Table1. Comparison of the Means of Use of Two Types of Strategies at Intermediate Level

\begin{tabular}{|c|c|c|c|c|}
\hline Learning strategy & Mean & $\mathrm{N}$ & Std. Deviation & Std. Error Mean \\
\hline Metacognitive & 2.73 & 60 & .44 & .05 \\
\hline Cognitive & 3.74 & 60 & .47 & .06 \\
\hline
\end{tabular}

As Table 1 displays, the mean of use of metacognitive strategies is less than the mean of cognitive strategies for intermediate level. Thus, we could say that the most common vocabulary learning strategies for intermediate learners are cognitive strategies.

\subsection{Metacognitive and Cognitive Strategies in Advanced Level}

Table 2 shows the means of advanced level in metacognition and cognition strategy. As Table 2 displays, the mean of metacognitive strategies is almost double the mean of cognitive strategies for advanced learners.

Table2. Comparison of the Means of Use of Two Types of Strategies at Advanced Level

\begin{tabular}{|c|c|c|c|c|}
\hline Learning strategy & Mean & $\mathrm{N}$ & Std. Deviation & Std. Error Mean \\
\hline Metacognitive & 4.097 & 60 & .35 & .04 \\
\hline Cognitive & 2.743 & 60 & .51 & .06 \\
\hline
\end{tabular}

The most frequently used vocabulary learning strategies among advanced level are metacognitive strategies.

\section{Discussion}


The results of the study demonstrated that cognitive strategies were the most frequently used strategies and metacognitive strategies were the least frequently used strategies among intermediate learners. According to Oxford (1990), cognitive strategies are found to be the most popular strategies with language learners and crucial in learning a new language. Following this, the results of a study by Schmitt (1997) demonstrated that social and metacognitive strategies are less frequently used by the participants. However, cognitive strategies for conscious learning are much more valued by the participants than metacognitive ones which are related to planning and evaluating the language process. However, results of this study are different from the research done by Law Bik Yuk (2003). He investigated vocabulary learning strategies of 80 Chinese EFL learners studying at a secondary school. He used interviews, a survey and think-aloud tasks. The results of his study showed that metacognitive strategies are the most frequently used strategies and cognitive strategies are the second most frequently used strategies. The results of the current study are congruent with the result of Cengizhan (2011). In his research, various vocabulary learning strategies are used by foreign language learners. In the study, a questionnaire containing 41 statements was given to 10th and 11th classes of Edirne Teacher Training High School. The results indicated that the most preferred vocabulary learning strategies were metacognitive strategies among 10th and 11th classe students. On the other hand, it was observed that cognitive strategies were the least preferred vocabulary learning strategies.

However, the results of the current study are similar to the research done by Nacera (2010), which focused on the use of language learning strategies and their relation with vocabulary size. The study consisted of 45 second year students graduating in English language in the University of Mouloud Mammeri of Tizi Ouzono.

The study applied Oxford 'Strategy Inventory' and 'The University World Level Test' which was adapted by Beglar, et al., (2000) to measure the vocabulary size. Results showed that the learners utilized a wider range of direct and indirect learning strategies. Result also showed that metacognitive strategies were used more often than all other types of vocabulary learning strategies. Another study whose findings are identical to ours is the research done by Tajedin (2001). He investigated the use of learning strategies, gender, language proficiency and learning situation. He utilized Oxford's (1990) 80 item questionnaire and identified that Iranian learners used metacognitive strategies more frequently and affective strategies less frequently than other learning strategies.

In sum, as mentioned before, findings revealed that metacognitive strategies were the most frequently used strategies and cognitive strategies were the least frequently used strategies among advanced levels.

\section{REFERENCES}

Anderson, N. (2002). Using telescopes, microscopes, and kaleidoscopes to put metacognition into perspective. TESOL Matters, 12(4), 1-10.

Bennett, P. (2006). An evaluation of vocabulary teaching in an intensive study program. Unpublished MA thesis. University of Birmingham, Birmingham. United Kingdom.

Cengizhan, L. (2011). Vocabulary learning strategies: A case of Edirne Anatolian high school. Science Direct, 15, 1870-1874.

GU, Y. \& Johnson, R.K. (1996). Vocabulary learning strategies and language learning outcomes. Language learning, 46(4),643-79.

Hedge, T. (2011) .Teaching and learning in the language classroom. Hong Kong: Oxford University Press.

Law Bik Yuk, S. (2003). Vocabulary learning strategies: A case study of form four students in a 
Chinese-medium secondary school. University of Hong Kong, Hong Kong.

Nacera, A. (2010). Language learning strategies and the vocabulary size. Science Direct, 2, 40214025.

Nation, P. (2001). Learning vocabulary in another language. Cambridge: Cambridge University Press.

Oxford, R. (1990). Language learning strategies: What every teacher should know. New York: Newbury House.

Read, J. (2000). Assessing vocabulary. Cambridge: Cambridge University Press.

Richards, J.C. \& Renadya, W.A. (2002). Methodology in language teaching: An anthology of current practice. U.S.A: Cambridge University Press.

Ruutmets, K. (2005). Vocabulary learning strategies in studing English as a foreign language. Master Dissertation. Available online: http//www.utlib.ee/ekollekt/diss/mag/2005/b17557100/ruutmets. pdf.

Schmitt, N. (2000). Vocabulary in language teaching. New York: Cambridge University Press,

Schmitt, N. (1997). Vocabulary: Description, acqusition and pedagogy.

Tajedin, Z. (2009). Language learning strategies: A strategy-based approach to L2 learning strategic competence, and test validation. Unpublished doctoral dissertation. Allameh Tabatabaee University, Tehran, Iran. Avaliable online: www.irandoc.ir.

Takac, V. P. (2008). Vocabulary learning strategies and second language acqusition .Clevedon, UK: Multilingual Matters.

William, J. (2006). Combining communication strategies and vocabulary development. The Internet TESL Journal, 7(2), 222-226.

Xhaferi, B. \& Xhaferi, G. (2008). Vocabulary learning strategies used by students at seeu in terms of gender and teachers' attitudes toward teaching vocabulary. Unpublished MA thesis, University of "Sv. Kliment Ohridski", Shkup.

Yamato, R. (2000). Awareness and real use of reading strategies. JALT Journal, 22,140-164. 